\title{
GTPase Nras
}

National Cancer Institute

\section{Source}

National Cancer Institute. GT Pase Nras. NCI Thesaurus. Code C17384.

GT Pase NRas (189 aa, $\sim 21 \mathrm{kDa}$ ) is encoded by the human NRAS gene. This protein is involved in the mediation of GT Pase-dependent signaling. 